\title{
Vector-field dynamic x-ray (VF-DXR) using optical flow method in patients with chronic obstructive pulmonary disease
}

Takuya Hino ${ }^{*}$ (D), Akinori Tsunomori ${ }^{2}$, Akinori Hata ${ }^{1,3}$, Tomoyuki Hida ${ }^{4}$, Yoshitake Yamada ${ }^{5}$, Masako Ueyama ${ }^{6}$, Tsutomu Yoneyama ${ }^{2}$, Atsuko Kurosaki ${ }^{7}$, Takeshi Kamitani ${ }^{4}$, Kousei Ishigami ${ }^{4}$, Takenori Fukumoto ${ }^{2}$, Shoji Kudoh ${ }^{8}$ and Hiroto Hatabu ${ }^{1}$

\begin{abstract}
Background: We assessed the difference in lung motion during inspiration/expiration between chronic obstructive pulmonary disease (COPD) patients and healthy volunteers using vector-field dynamic x-ray (VF-DXR) with optical flow method (OFM).

Methods: We enrolled 36 COPD patients and 47 healthy volunteers, classified according to pulmonary function into: normal, COPD mild, and COPD severe. Contrast gradient was obtained from sequential dynamic x-ray (DXR) and converted to motion vector using OFM. VF-DXR images were created by projection of the vertical component of lung motion vectors onto DXR images. The maximum magnitude of lung motion vectors in tidal inspiration/ expiration, forced inspiration/expiration were selected and defined as lung motion velocity (LMV). Correlations between LMV with demographics and pulmonary function and differences in LMV between COPD patients and healthy volunteers were investigated.

Results: Negative correlations were confirmed between LMV and \% forced expiratory volume in one second $\left(\% \mathrm{FEV}_{1}\right)$ in the tidal inspiration in the right lung (Spearman's rank correlation coefficient, $\left.r_{\mathrm{s}}=-0.47, p<0.001\right)$ and the left lung $\left(r_{s}=-0.32, p=0.033\right)$. A positive correlation between LMV and $\% F E V_{1}$ in the tidal expiration was observed only in the right lung $\left(r_{\mathrm{s}}=0.25, p=0.024\right)$. LMVs among normal, COPD mild and COPD severe groups were different in the tidal respiration. COPD mild group showed a significantly larger magnitude of LMV compared with the normal group.
\end{abstract}

Conclusions: In the tidal inspiration, the lung parenchyma moved faster in COPD patients compared with healthy volunteers. VF-DXR was feasible for the assessment of lung parenchyma using LMV.

Keywords: Lung, Optic flow, Pulmonary disease (chronic obstructive), Radiography (thoracic), Respiratory function tests

\footnotetext{
* Correspondence: thino@bwh.harvard.edu

${ }^{1}$ Center for Pulmonary Functional Imaging, Department of Radiology, Brigham and Women's Hospital and Harvard Medical School, 75 Francis

Street, Boston, MA 02115, USA

Full list of author information is available at the end of the article
}

\section{Springer Open}

(c) The Author(s) under exclusive licence to European Society of Radiology. 2022 Open Access This article is licensed under a Creative Commons Attribution 4.0 International License, which permits use, sharing, adaptation, distribution and reproduction in any medium or format, as long as you give appropriate credit to the original author(s) and the source, provide a link to the Creative Commons licence, and indicate if changes were made. The images or other third party material in this article are included in the article's Creative Commons licence, unless indicated otherwise in a credit line to the material. If material is not included in the article's Creative Commons licence and your intended use is not permitted by statutory regulation or exceeds the permitted use, you will need to obtain permission directly from the copyright holder. To view a copy of this licence, visit http://creativecommons.org/licenses/by/4.0/. 


\section{Key points}

- Lung motion velocity in tidal respiration showed a moderate correlation with percent predicted forced expiratory volume in one second $\left(\% \mathrm{FEV}_{1}\right)$.

- Chronic obstructive pulmonary disease (COPD) mild group had larger lung motion velocity than the normal group in tidal respiration.

- The lung parenchyma moved faster in COPD patients than in normal subjects.

\section{Background}

Chronic obstructive pulmonary disease (COPD) is associated with increased mortality and comorbidity $[1,2]$. It is widely accepted that the dysfunction of muscles as well as lung hyperinflation and chest wall remodeling causes the decreased mobility of the thorax [3]. Lung motion of normal subjects was assessed with fourdimension computed tomography (CT) applying robust feature matching, nonrigid point cloud registration, strain measurement, and sparse motion field method [4-7]. However, these studies did not completely reflect physiological lung motion because they were studied in the supine position, not in the standing position.

Recently, dynamic x-ray (DXR) using a flat panel detector with a large field of view was introduced. Previous studies have already shown the efficacy of DXR in measuring diaphragm or rib motion as well as projected lung area during a particular breathing phase in the standing position [8-13]. DXR enabled to obtain sequential images with high temporal resolution [14, 15]. The optical flow method (OFM) is one of the concentration gradient methods, providing visualization of moving objects by mathematical conversion of spatiotemporal concentration gradient to apparent motion [16]. This theory was based on three preconditions of movement between intervals as follows: unchanged luminance distribution, spatiotemporal differentiation, and minute movement. The OFM is applied to the recognition of moving objects or the quantification of movement in various situations [17-19]. Recent studies have demonstrated that physiological lung motion was potentially visualized with vector-field dynamic x-ray (VF-DXR) with sequential images of DXR using OFM [20]. During the spread of COVID-19, it may be helpful for this technique to provide the pulmonary functional data without physical contact between mouth and equipment. Even after the pandemic, the noncontact nature of this technique will be helpful against the possible emerging infection or novel respiratory diseases in the future. The absence of intrinsic circuit resistance is another unique characteristic of this new approach using dynamic $\mathrm{x}$-ray.

We hypothesized that the altered motion of the lung parenchyma will be observed in patients with COPD when compared with that of healthy volunteers. The aim of this study is to assess the quantitative difference of dynamic lung motion between patients with COPD and healthy volunteers using VF-DXR with OFM.

\section{Methods \\ Study population}

This retrospective study was approved by the ethics committee and performed in accordance with the Declaration of Helsinki. The cohort was prospectively enrolled. Written informed consent was obtained from all the subjects prior to participation. From June 2009 to August 2011, consecutive COPD patients meeting the same inclusion criteria as those of previous studies were recruited [9, 11]: (1) clinical diagnosis of pure COPD based on clinical course, symptoms, chest CT examination, and pulmonary function test (PFT) with postbronchodilator inhalation; (2) exclusion of other respiratory diseases such as acute respiratory infection, bronchiectasis, or any type of interstitial lung disease; (3) current or former smokers; (4) $\geq 20$-year-old adults who gave informed consent, including for additional $\mathrm{x}$-ray exposure within tolerant range compared to conventional chest radiography; (5) no status of pregnancy, potential pregnancy, or lactation; (6) scheduled for conventional chest radiograph; (7) ability to follow instructions for tidal or forced breathing. All the COPD subjects were classified into spirometry grades from 1 to 4 by global initiative for chronic obstructive lung disease (GOLD) with corresponding percent predicted forced expiratory volume in one second $\left(\% \mathrm{FEV}_{1}\right)$ [21]. COPD mild group was defined as GOLD 1 or 2 (i.e., $\% \mathrm{FEV}_{1} \geq 50$ ), and COPD severe group was defined as GOLD 3 or 4 (i.e., $\% \mathrm{FEV}_{1}<50$ ) in this study.

On the other hand, healthy volunteers as a control group were also recruited from May 2013 to February 2014. The following inclusion criteria were the same as those of previous studies $[9,11]:(1) \geq 20$-year-old adults who gave informed consent, including for additional $\mathrm{x}$ ray exposure by DXR; (2) scheduled for conventional chest radiograph; (3) PFT results within normal limits, namely percent predicted vital capacity (\%VC) > 80\% and forced expiratory volume percent in one second divided by forced vital capacity $\left(\mathrm{FEV}_{1} \%\right)>70 \%$; (4) ability to follow instructions for forced or tidal breathing; (5) never smokers; (6) no status of pregnancy, potential pregnancy or lactation; (7) no past medical history of respiratory diseases.

The inclusion criteria were the same as those of previous studies [10, 12].

\section{Image acquisition}

Posteroanterior view of chest DXR examination in standing position was performed with a prototype $\mathrm{x}$-ray system (Konica Minolta Inc., Tokyo, Japan) composed of 
a flat panel detector (PaxScan 4030CB, Varian Medical Systems Inc., Salt Lake City, UT, USA) and a pulsed $\mathrm{x}$ ray generator (DHF-155HII) with cineradiography option (Hitachi Medical Corporation, Tokyo, Japan). During the examination, COPD patients took several tidal breaths and one forced breath separately, while normal subjects took several tidal breaths, followed by one forced breath. Conditions for DXR examination were the same as the previous reports [9-13]: tube voltage 100 $\mathrm{kVp}$; tube current $50 \mathrm{~mA}$; pulse duration of pulsed $\mathrm{x}$-ray $1.6 \mathrm{~ms}$; source-to-image distance $2 \mathrm{~m}$; additional filter $0.5 \mathrm{~mm} \mathrm{Al}$ plus $0.1 \mathrm{~mm} \mathrm{Cu}$. The additional filter was used to filter out soft $\mathrm{x}$-rays. The exposure time was approximately $10-15 \mathrm{~s}$. The pixel size was $388 \times 388 \mu \mathrm{m}$, the matrix size was $1024 \times 768$, and the overall image area was $40 \times 30 \mathrm{~cm}$. The dynamic image data, captured at 7.5-15 frames/s, were synchronized with the pulsed $\mathrm{x}$-ray, which prevented excessive radiation exposure to the subjects. The entrance surface dose was approximately 0.3-1.0 mGy. Each DXR image was processed with bone suppression and converted into video with 5 frames/s before application of the optical flow method.

\section{Image conversion to video using OFM}

Total variation regularization and robust L1 norm, TVL1, optical flow estimation were adopted for motion analysis [22]. The rectangle-shaped region of interest (ROI) including the unilateral lung field in the forced inspiratory phase was located on both sides of the video. The size of the ROI of either side was usually different. Then, a larger ROI was set symmetrically with the same horizontal level as a substitute for a smaller ROI. Bilateral lung fields within the ROI were subdivided into 4$\mathrm{cm}^{2}$ pixels to assess lung motion vector using OFM. In each pixel, the subtle interval difference in density between temporally successive DXR images with bone suppression was converted into motion vector using OFM implemented by OpenCV [23]. The obtained motion vectors were multiplied by five to represent motion/s. Only vertical motion vectors of all the pixels were superimposed on DXR images. The longest lung motion vector onto VF-DXR images in tidal inspiration, tidal expiration, forced inspiration, and forced expiration were extracted and defined as lung motion velocity (LMV). Downward direction of vectors was defined as positive direction.

\section{Data analysis}

Demographic data among normal, COPD mild, and COPD severe groups were tested using one-way analysis of variance on ranks. The difference in sex ratio among the three groups was compared using Fisher's exact test. Pulmonary function data such as tidal volume (TV), vital capacity (VC), \%VC, $\mathrm{FEV}_{1}, \mathrm{FEV}_{1} \%$, and $\% \mathrm{FEV}_{1}$ were assessed with one-way analysis of variance on ranks. The association of LMV with demographic data or

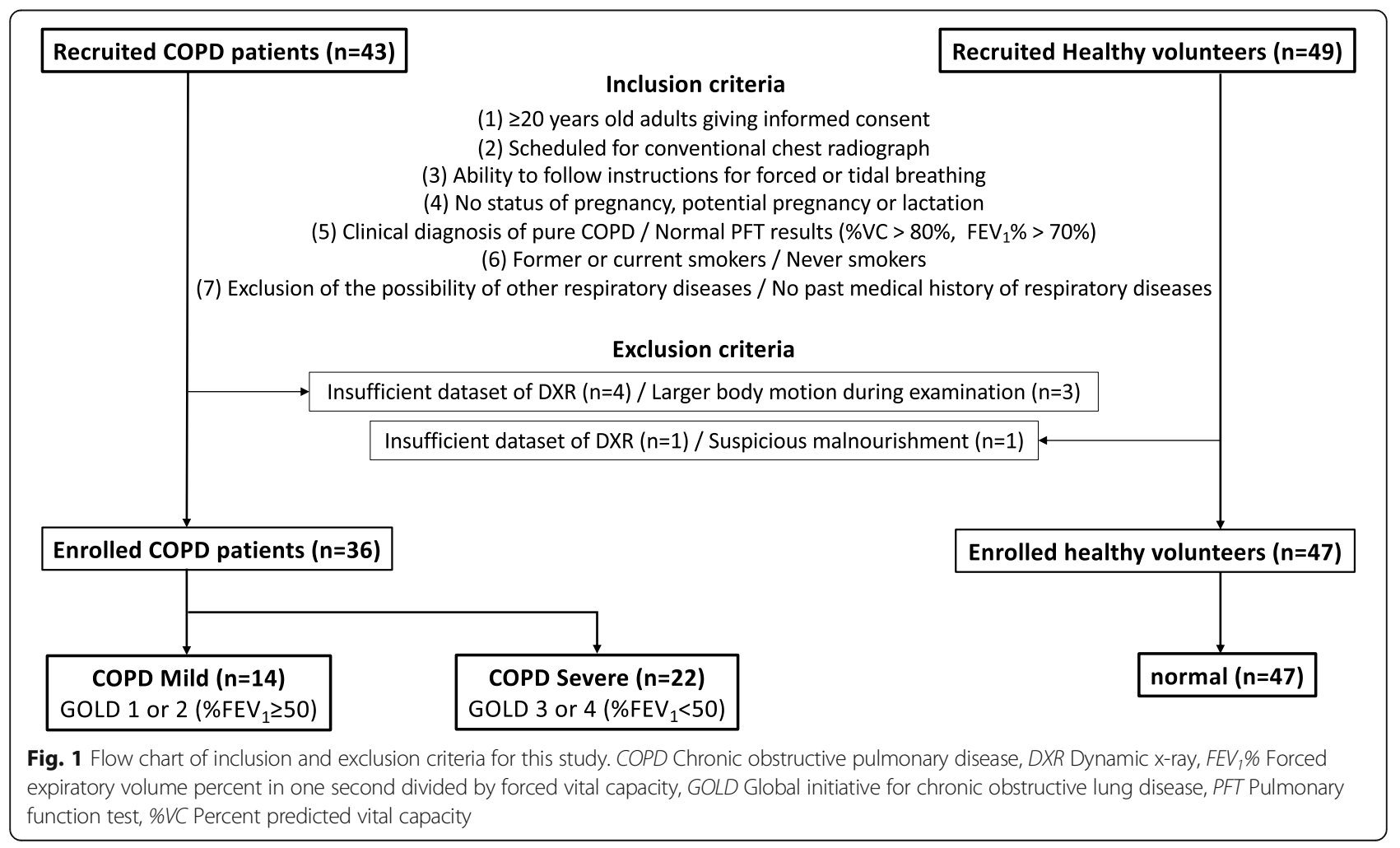


Table 1 Demographic data and PFTs among normal, COPD mild, and COPD severe groups

\begin{tabular}{|c|c|c|c|c|}
\hline \multirow[t]{2}{*}{ Variables } & \multirow{2}{*}{$\begin{array}{l}\text { Normal }(n=47) \\
\text { Median [IQR] }\end{array}$} & \multirow{2}{*}{$\begin{array}{l}\text { COPD mild }(n=14) \\
\text { Median [IQR] }\end{array}$} & COPD severe $(n=22)$ & \multirow{2}{*}{$\begin{array}{l}p \\
\text { value }\end{array}$} \\
\hline & & & Median [IQR] & \\
\hline Age (years) & $55[49,61]$ & $77.5[71.5,79]$ & $67.5[63.5,76.3]$ & $<0.001$ \\
\hline Sex, females/males & $27 / 20$ & $2 / 12$ & $3 / 19$ & $<0.001$ \\
\hline Height (cm) & $162.3[155,169.6]$ & $164.5[161.5,167]$ & $164.5[158.3,167.5]$ & 0.907 \\
\hline Weight (kg) & $61.2[51.6,66.3]$ & $57.9[54.6,62.5]$ & $50.0[47.0,60.8]$ & 0.210 \\
\hline $\mathrm{BMI}\left(\mathrm{kg} / \mathrm{m}^{2}\right)$ & $22.7[20.4,23.7]$ & $22.6[20.5,23.4]$ & $19.7[18.0,22.5]$ & 0.083 \\
\hline Smoking History & Never & Current or former & Current or former & \\
\hline GOLD, 1/2/3/4 & Not applicable & $4 / 10 / 0 / 0$ & $0 / 0 / 17 / 5$ & \\
\hline \multicolumn{5}{|l|}{ PFT } \\
\hline $\mathrm{TV}(\mathrm{L})$ & $0.60[0.50,0.98]$ & $1.09[0.75,1.23]$ & $0.84[0.72,0.97]$ & 0.006 \\
\hline VC (L) & $3.25[2.64,3.80]$ & $3.11[2.85,3.50]$ & $2.47[1.94,2.79]$ & $<0.001$ \\
\hline$\% \mathrm{VC}$ & $106.1[99.9,117.5]$ & $104.3[91.5,115.2]$ & $79.9[68.9,90.4]$ & $<0.001$ \\
\hline $\mathrm{FEV}_{1}(\mathrm{~L})$ & $2.58[2.18,3.19]$ & $1.72[1.56,1.98]$ & $0.93[0.82,1.03]$ & $<0.001$ \\
\hline $\mathrm{FEV}_{1} \%$ & $81.6[79.0,85.7]$ & $58.8[53.6,60.7]$ & $41.2[36.6,44.8]$ & $<0.001$ \\
\hline$\% \mathrm{FEV}_{1}$ & $105.2[98.7,113.8]$ & $70.2[59.1,79.4]$ & $37.2[31.2,42.4]$ & $<0.001$ \\
\hline
\end{tabular}

Demographic data including age, height, weight, and BMI were assessed with one-way analysis of variance. Sex distribution was evaluated with Fisher's exact test. Each pulmonary functional data was examined with one-way analysis of variance on ranks. BMI Body mass index, COPD Chronic obstructive pulmonary disease, $F E V_{1}$ Forced expiratory volume in one second; $F E V_{1} \%$ Forced expiratory volume percent in one second divided by forced vital capacity, \%FEV, Percent predicted forced expiratory volume in one second; GOLD Global initiative for chronic obstructive lung disease; IQR Interquartile range, PFT Pulmonary function tests; TV Tidal volume, VC Vital capacity, \%VC Percent predicted vital capacity

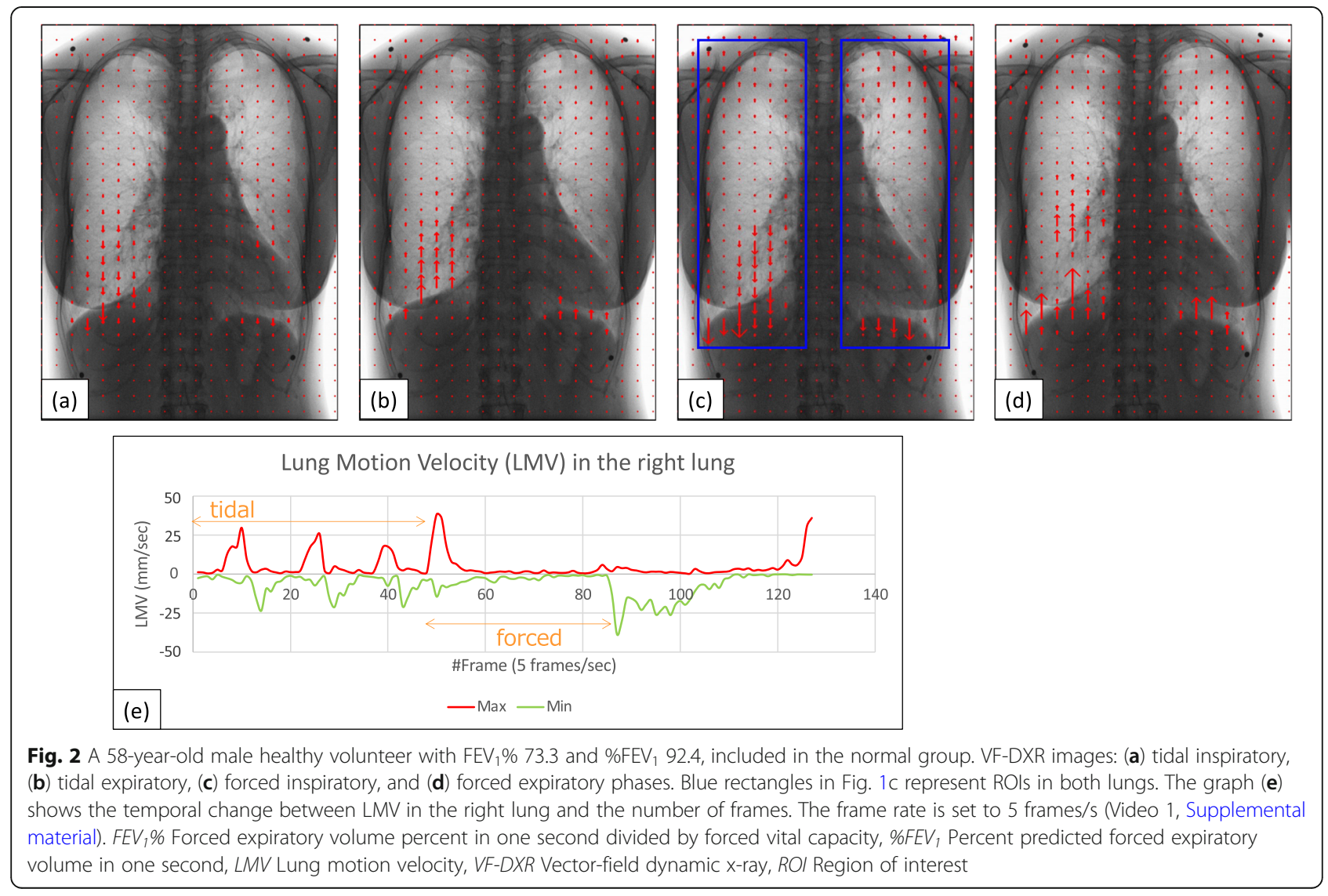



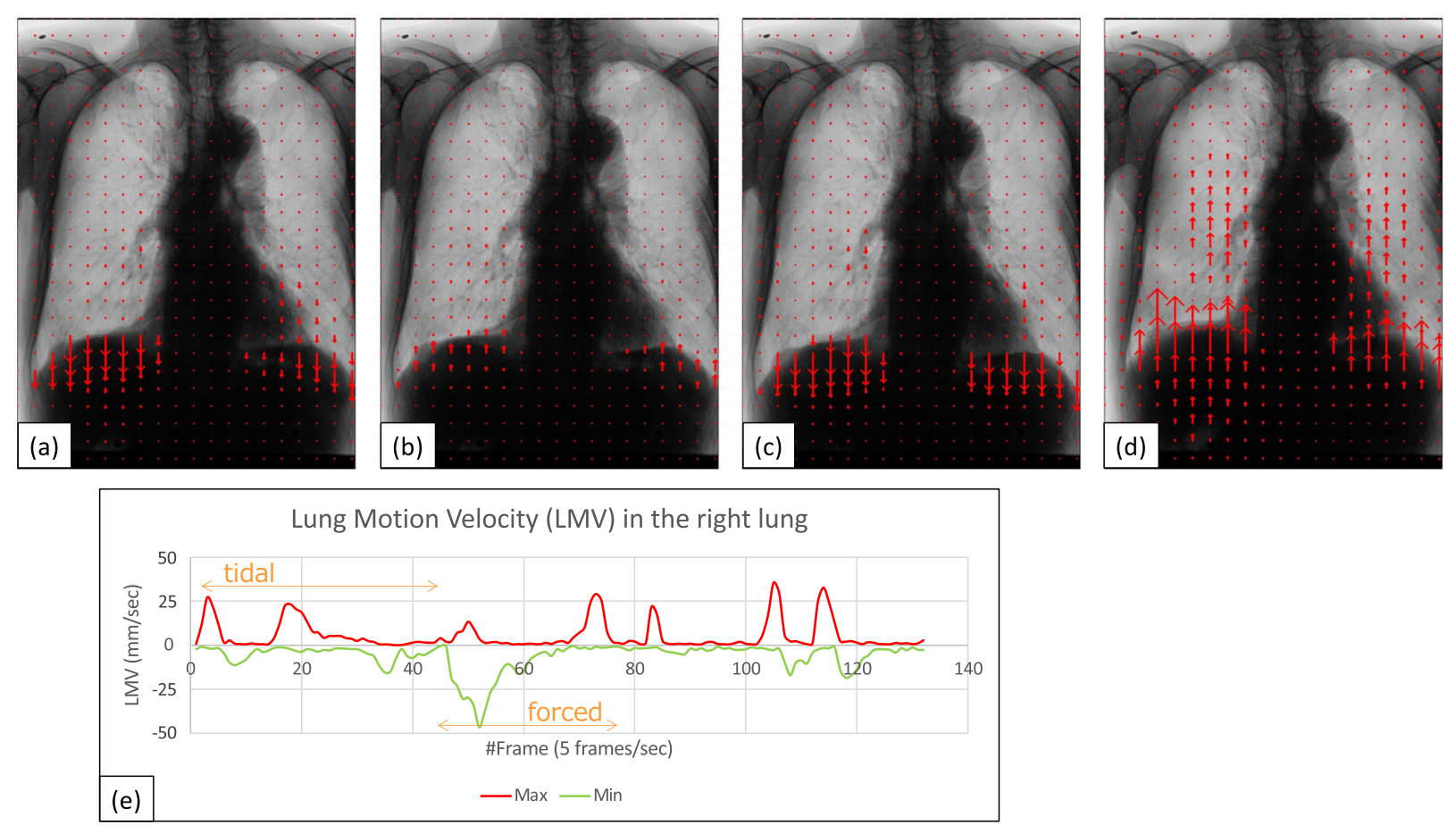

Fig. 3 A 53-year-old made, COPD patient with $\mathrm{FEV}_{1} \% 60.3$ and \%FEV 179.6 , which meets the criteria of GOLD 2, COPD mild group. VF-DXR images: (a) tidal inspiratory, (b) tidal expiratory, (c) forced inspiratory, and (d) forced expiratory phase. The graph (e) shows the temporal change between LMV in the right lung and the number of frames. The frame rate is set to 5 frames $/ \mathrm{s}$. COPD Chronic obstructive pulmonary disease, $F E V, \%$ Forced expiratory volume percent in one second divided by forced vital capacity, \%FEV 1 Percent predicted forced expiratory volume in one second, GOLD Global initiative for chronic obstructive lung disease, LMV Lung motion velocity, VF-DXR Vector-field dynamic x-ray

pulmonary function was analyzed with Spearman's rank correlation coefficient. Scatter plots of $\% \mathrm{FEV}_{1}$ versus LMV in each phase or side were visualized. The difference in LMV in both lungs in tidal and forced inspiratory and expiratory phases among three groups was analyzed with one-way analysis of variance on ranks. Post-hoc multiple comparisons were made using the Holm-Bonferroni method. A two-group comparison of LMV between normal subjects and COPD patients were also performed using the Mann-Whitney $U$ test.

Statistical assessment was performed using R 4.0.3 ( $\mathrm{R}$ Foundation for Statistical Computing, Vienna, Austria) with the EZR graphical user interface (Saitama Medical Center, Jichi Medical University, Saitama, Japan) [24, 25]. More precisely, EZR is a modified version of $\mathrm{R}$ commander designed to add statistical functions frequently used in biostatistics. In each test, a two-sided $p$ value of less than 0.05 was considered statistically significant.

\section{Results}

Inclusion and exclusion criteria

The flow chart of inclusion and exclusion criteria are summarized in Fig. 1. Forty-three COPD patients as well as 49 healthy volunteers were meeting the inclusion criteria. Seven COPD patients and two healthy volunteers were excluded due to incomplete dataset, body motion, or suspicious malnourishment. Finally, a total of 36 COPD and 47 healthy subjects were analyzed in this study. Fourteen patients were classified as COPD mild, and 22 patients as COPD severe. Forty-seven healthy volunteers served as normal subjects, which is the same as those of the previous study [9].

\section{Demographic data and example cases}

Demographic data and pulmonary function tests data among normal, COPD mild, and COPD severe groups were summarized in Table 1. Age, sex, and pulmonary function were different among the three groups with statistical significance $(p<0.001)$; COPD mild and severe groups mainly consisted of elderly males with a pulmonary functional disorder. The examples of VF-DXR images of the thorax during tidal and forced respiratory cycles are shown for normal (Fig. 2), COPD mild (Fig. 3 ), and COPD severe groups (Fig. 4). LMVs were largest in the lower lung fields in the tidal and forced inspiratory phases, and smallest in lower lung fields in the tidal and forced expiratory phases. 
The correlation of LMV with demographic data

Scatter plots with LMV versus $\% \mathrm{FEV}_{1}$ in the tidal inspiratory and expiratory phases were shown in Fig. 5. There were significant negative correlations between LMV and $\% \mathrm{FEV}_{1}$ in the tidal inspiratory phase in both lungs (right, $r_{\mathrm{s}}=-0.47, p<0.001$; left, $r_{\mathrm{s}}=-0.32, p=$ 0.003). A significant positive correlation between LMV and $\% \mathrm{FEV}_{1}$ in the tidal expiratory phase was observed in the right lung $\left(r_{\mathrm{s}}=0.25, p=0.024\right)$, but not in the left lung. Tables 2 and 3 demonstrate the degree of correlations between LMV and demographic data and pulmonary function tests in tidal and forced inspiratory and expiratory phases in the right lung (Table 2) and in the left lung (Table 3). Mild to moderate correlation between LMV and $\% \mathrm{FEV}_{1}$ was observed in both lungs in the tidal inspiratory and expiratory phases. LMV in the tidal inspiratory and expiratory phases in the right lung also showed mild to moderate correlation with $\mathrm{FEV}_{1}$, $\mathrm{FEV}_{1} \%$, and age (Tables 2 and 3 ).

\section{Difference in LMV among three groups}

LMVs among normal, COPD mild, and COPD severe groups were summarized in Table 4. LMVs among groups were different in the tidal inspiratory and expiratory phases, which was confirmed by one-way analysis of variance on ranks. Post-hoc multiple comparison analyses with the Holm-Bonferroni method showed that the COPD mild group has a significantly larger magnitude of LMV compared with the normal group (Fig. 6). A similar trend was also observed in COPD severe group compared to the normal group, while the statistical significance was confirmed in only LMV in tidal inspiration in the right lung (Fig. 6). In two-group comparisons, the lung parenchyma moved faster in COPD patients compared with normal subjects in the tidal respiration in both lungs $(p<0.004)$ except for the tidal expiration in the left lung (Fig. 7).

\section{Discussion}

This paper first demonstrated the quantitative assessment of lung motion in the standing position, using DXR with OFM. OFM was considered optimal to visualize lung motion due to the concentration gradient calculated from sequential DXR images with high spatiotemporal resolution. The current study demonstrated that VF-DXR with OFM is applicable to clinical research. Previous studies have reported the difference of pixel value change or diaphragm motion between normal subjects and COPD patients with DXR $[8,9]$. The lung moves rhythmically in cooperation with the diaphragm and thoracic cage. It was expected
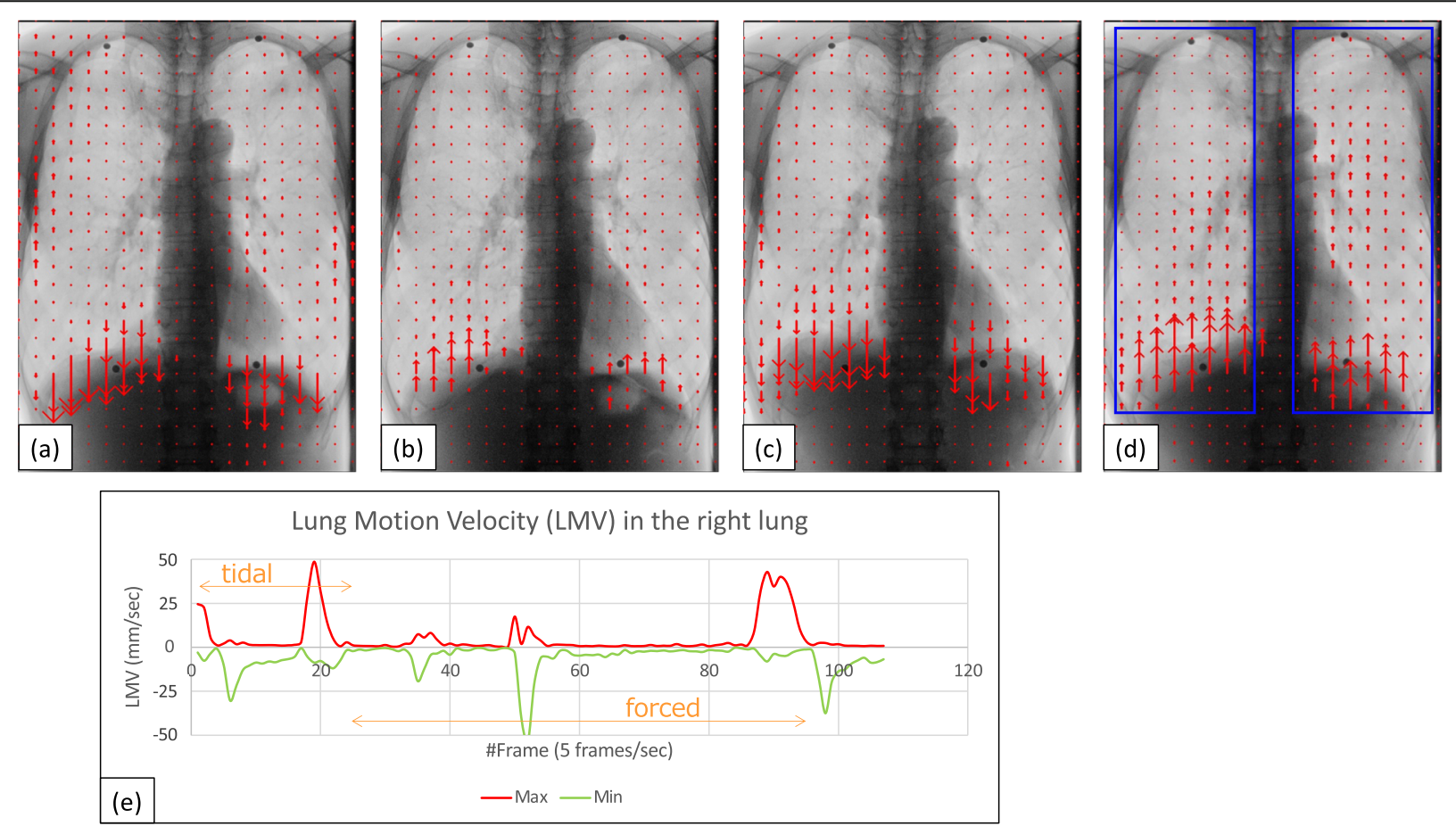

Fig. 4 A 65-year-old male, COPD patient with $\mathrm{FEV}_{1} \% 38.5$ and \%FEV 1 16.3, which meets the criteria of GOLD 4, COPD Severe group. Blue rectangles in Fig. 3 (d) represent bilateral ROIs. VF-DXR images in (a) tidal inspiratory, (b) tidal expiratory, (c) forced inspiratory, and d forced expiratory phase. Blue rectangles represent bilateral ROls. (e) The graph shows the temporal change between LMV in the right lung and the number of frames. The frame rate is set to 5 frames/ $\mathrm{s}$ (Video 2 in the Supplemental material). COPD Chronic obstructive pulmonary disease, FEV ${ }_{1} \%$ Forced expiratory volume percent in one second divided by forced vital capacity, \%FEV, Percent predicted forced expiratory volume in one second, GOLD Global initiative for chronic obstructive lung disease, LMV Lung motion velocity, $R O /$ region of interest, VF-DXR Vector-field dynamic x-ray 
(a) tidal inspiration

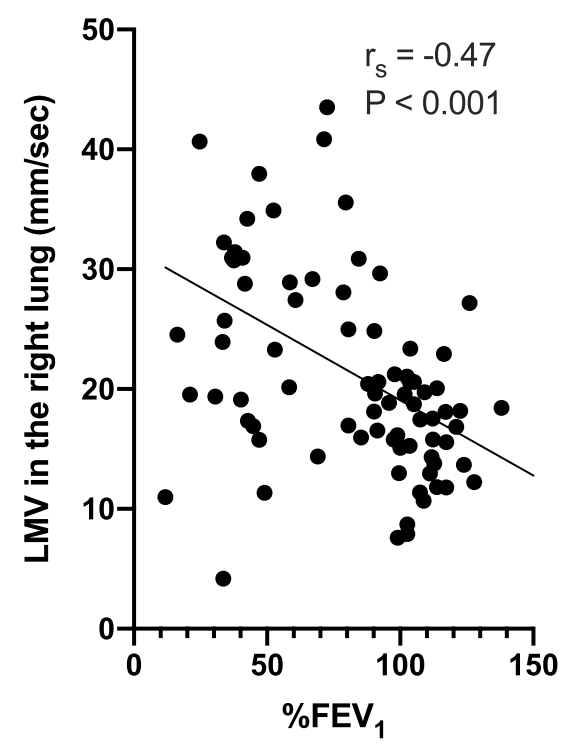

(c) tidal expiration

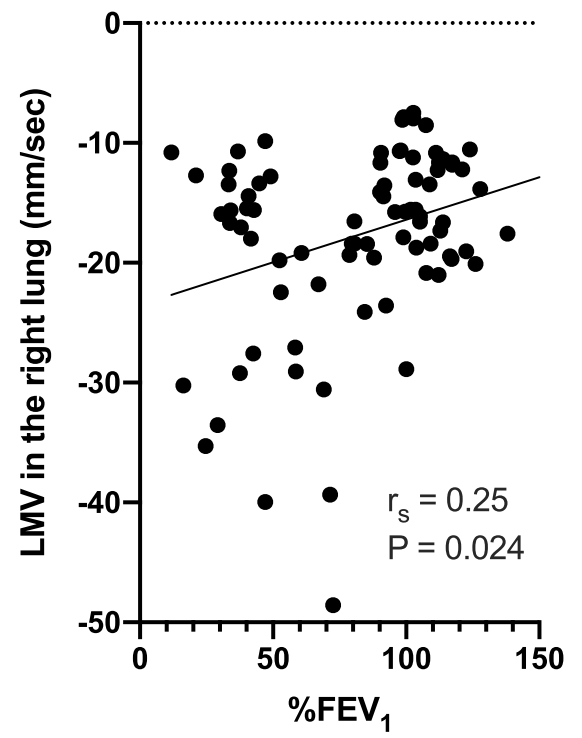

(b) tidal inspiration

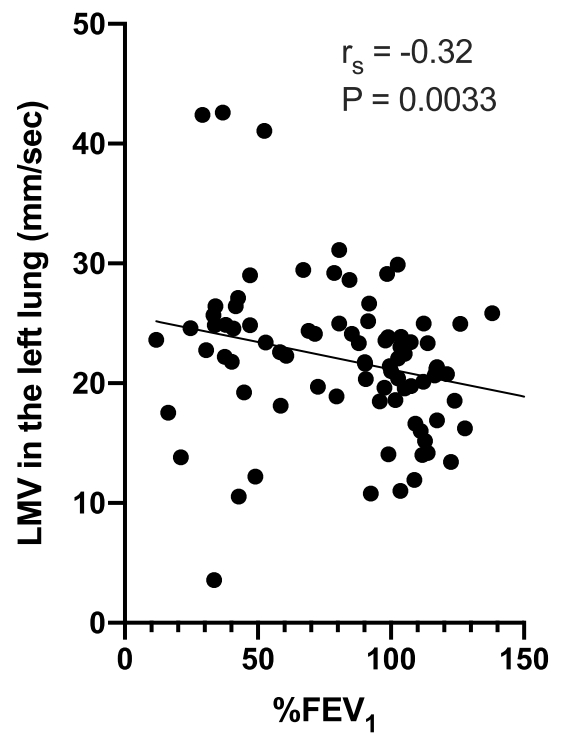

(d) tidal expiration

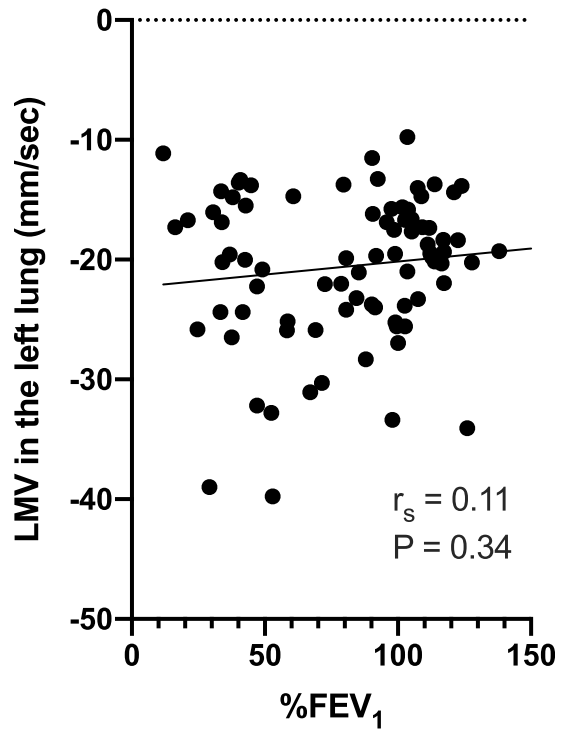

Fig. 5 Scatter plots of \% FEV 1 and bilateral LMV in tidal respiratory phase with approximate line. LMV in the tidal inspiration phase versus \%FEV ${ }_{1}$ in the right lung (a) and in the left lung (b). LMV in the tidal expiration phase versus \%FEV 1 in the right lung (c) and in the left lung (d). In each phase, the statistically significant correlation between \%FEV ${ }_{1}$ and LMV in tidal inspiration in both lungs as well as those between \%FEV ${ }_{1}$ and LMV in tidal expiration in the right lung was indicated by the Spearman rank correlation coefficient. COPD Chronic obstructive pulmonary disease, $\% F E V_{1}$ Percent predicted forced expiratory volume in one second, LMV Lung motion velocity, $r_{s}$ Spearman's rank correlation coefficient 
Table 2 Correlation between lung motion velocity in the right lung and demographic data

\begin{tabular}{|c|c|c|c|c|c|c|c|c|}
\hline \multirow[t]{2}{*}{ Variables } & \multicolumn{2}{|l|}{ Tidal inspiration } & \multicolumn{2}{|l|}{ Tidal expiration } & \multicolumn{2}{|l|}{ Forced inspiration } & \multicolumn{2}{|l|}{ Forced expiration } \\
\hline & $\mathrm{r}_{\mathrm{s}}[95 \% \mathrm{Cl}]$ & $p$ value & $\mathrm{r}_{\mathrm{s}}[95 \% \mathrm{Cl}]$ & $p$ value & $\mathrm{r}_{\mathrm{s}}[95 \% \mathrm{Cl}]$ & $p$ value & $\mathrm{r}_{\mathrm{s}}[95 \% \mathrm{Cl}]$ & $p$ value \\
\hline Age & $0.34[0.13,0.52]$ & $0.002^{* *}$ & $-0.32[-0.51,-0.11]$ & $0.003^{* *}$ & $0.09[-0.13,0.31]$ & 0.404 & $-0.27[-0.46,-0.05]$ & $0.015^{*}$ \\
\hline Sex & $0.20[-0.02,0.41]$ & 0.068 & $-0.08[-0.30,0.14]$ & 0.446 & $0.11[-0.11,0.33]$ & 0.315 & $-0.25[-0.45,-0.03]$ & $0.023^{*}$ \\
\hline Height & $0.07[-0.15,0.29]$ & 0.500 & $-0.04[-0.26,0.18]$ & 0.719 & $0.08[-0.14,0.30]$ & 0.450 & $-0.30[-0.49,-0.08]$ & $0.007^{* *}$ \\
\hline Weight & $0.06[-0.16,0.28]$ & 0.571 & $-0.05[-0.27,0.17]$ & 0.656 & $0.05[-0.17,0.27]$ & 0.657 & $-0.26[-0.46,-0.04]$ & $0.016^{*}$ \\
\hline BMl & $0.06[-0.17,-0.28]$ & 0.595 & $-0.07[-0.28,0.16]$ & 0.552 & $0.05[-0.18,0.27]$ & 0.679 & $-0.16[-0.37,0.07]$ & 0.157 \\
\hline TV & $0.14[-0.08,0.35]$ & 0.198 & $-0.17[-0.38,0.05]$ & 0.120 & $0.16[-0.06,0.37]$ & 0.144 & $-0.27[-0.46,-0.05]$ & $0.015^{*}$ \\
\hline VC & $-0.19[-0.40,0.03]$ & 0.073 & $0.12[-0.10,0.33]$ & 0.278 & $-0.03[-0.25,0.19]$ & 0.764 & $-0.14[-0.35,0.08]$ & 0.194 \\
\hline$\% \mathrm{VC}$ & $-0.26[-0.46,-0.04]$ & $0.017^{*}$ & $0.11[-0.11,0.33]$ & 0.309 & $-0.05[-0.27,0.18]$ & 0.689 & $-0.05[-0.27,0.18]$ & 0.664 \\
\hline $\mathrm{FEV}_{1}$ & $-0.40[-0.57,-0.20]$ & $<0.001^{* *}$ & $0.26[0.05,0.46]$ & $0.016^{*}$ & $-0.08[-0.30,0.18]$ & 0.448 & $0.08[-0.14,0.30]$ & 0.454 \\
\hline $\mathrm{FEV}_{1} \%$ & $-0.42[-0.59,-0.22]$ & $<0.001^{* *}$ & $0.25[0.03,0.45]$ & $0.021^{*}$ & $-0.16[-0.37,-0.06]$ & 0.146 & $0.25[0.03,0.44]$ & $0.025^{*}$ \\
\hline$\% \mathrm{FEV}_{1}$ & $-0.47[-0.63,-0.28]$ & $<0.001^{* *}$ & $0.25[0.03,0.45]$ & $0.024^{* *}$ & $-0.10[-0.31,0.12]$ & 0.385 & $0.18[-0.05,0.25]$ & 0.114 \\
\hline
\end{tabular}

Spearman's rank correlation coefficient $\left(r_{\mathrm{s}}\right)$ was calculated. ${ }^{*} p<0.05 ;{ }^{* *} p<0.01$. BMI Body mass index, $\mathrm{Cl}$ Confidence interval, $F E V_{1}$ Forced expiratory volume in one second, $F E V_{1} \%$ Forced expiratory volume percent in one second divided by forced vital capacity, \%FEV 1 Percent predicted forced expiratory volume in one second, GOLD Global initiative for chronic obstructive lung disease, LMV Lung motion velocity, TV Tidal volume, VC Vital capacity; \%VC Percent predicted vital capacity

that the lung motion between normal subjects and COPD patients is different.

Tanaka et al. [14] have reported DXR had the potential to visualize vector-field of lung motion using the crosscorrelation method. OFM was initially proposed as one of the markerless tracking methods for lung tumors in chest radiographs [26]. OFM can visualize motion velocity with higher spatial resolution than the crosscorrelation method [27]. Ichiji et al. [28] first applied OFM to sequential $x$-ray images to track the real-time motion of lung tumors, although the lung parenchymal motion itself was not studied in the paper. Recently, the feasibility of VF-DXR with OFM for lung parenchyma motion analysis was reported [21]. However, quantification of the motion vector of VF-DXR has not been assessed yet.

In this study, COPD patients showed larger LMV in tidal inspiration, compared with normal subjects. Peripheral muscle atrophy and dysfunction can cause hyperinflation followed by abnormal position or movement of the lower rib cage [29]. These mechanisms might induce larger LMV. Hyperinflation of the lungs, followed by a flattened diaphragm, might also contribute to larger LMV in COPD patients. The laterality of LMV may attribute to the lower level of the left diaphragm; the left lower lung field can move longer or faster, whereas the right diaphragm is oppressed by the liver. Heart or stomach gas are also possible causes of laterality.

Koyama et al. [30] assessed three-dimensional lung motion of COPD patients obtained by thin-sliced inspiratory and expiratory $\mathrm{CT}$ images in the supine position. They focused on the non-rigid registration model to visualize 3D motion vectors. They showed that craniocaudal lung motion was correlated with $\% \mathrm{FEV}_{1}$ in COPD patients. On the other hand, VFDXR adopted OFM as a simpler technique. VF-DXR is performed in the standing position without lateral images. VF-DXR can collect sequential images of continuous respiratory phases. VF-DXR in the standing position may be able to represent dynamic and physiological respiration more appropriately than $\mathrm{CT}$. The lower radiation exposure compared with $\mathrm{CT}$ is another advantage of VF-DXR. The efficacy of OFM toward respiratory diseases other than COPD has not been proved yet. However, it has the potential to make the application for motion analysis of interstitial pneumonia or postoperative adhesion.

This study has several limitations. First, it has a small sample size: only 47 normal and 36 COPD subjects were analyzed. Reassessment with larger cases will be required to reconfirm the results of this study. Second, we focused on only the maximum vector in some phases, which did not perfectly reproduce the real lung motion or LMV. Third, this study depended on only the visual assessment of videos. It is also a problem that VF-DXR could not be compared with actual lung motion. Fourth, the ventrodorsal motion could not be analyzed owing to the lack of lateral image data in COPD patients.

In conclusion, the lung parenchyma moved faster in COPD patients compared with normal subjects in the tidal respiration. Significant negative correlations were observed between LMV and $\% \mathrm{FEV}_{1}$ in the tidal 
Table 3 Correlation between lung motion velocity in the left lung and demographic data

\begin{tabular}{|c|c|c|c|c|c|c|c|c|}
\hline \multirow[t]{2}{*}{ Variables } & \multicolumn{2}{|l|}{ Tidal inspiration } & \multicolumn{2}{|l|}{ Tidal expiration } & \multicolumn{2}{|c|}{ Forced inspiration } & \multicolumn{2}{|l|}{ Forced expiration } \\
\hline & $\mathrm{r}_{\mathrm{s}}[95 \% \mathrm{Cl}]$ & $p$ value & $\mathrm{r}_{\mathrm{s}}[95 \% \mathrm{Cl}]$ & $p$ value & $\mathrm{r}_{\mathrm{s}}[95 \% \mathrm{Cl}]$ & $p$ value & $\mathrm{r}_{\mathrm{s}}[95 \% \mathrm{Cl}]$ & $p$ value \\
\hline Age & $0.14[-0.08,0.35]$ & 0.199 & $-0.17[-0.37,0.06]$ & 0.135 & $-0.02[-0.24,0.20]$ & 0.852 & $-0.19[-0.40,0.03]$ & 0.079 \\
\hline Sex & $0.27[0.05,0.47]$ & $0.013^{*}$ & $-0.10[-0.32,0.12]$ & 0.348 & $0.18[-0.05,0.38]$ & 0.110 & $-0.27[-0.46,-0.05]$ & $0.013^{*}$ \\
\hline Height & $0.08[-0.15,0.29]$ & 0.500 & $-0.06[-0.27,0.17]$ & 0.612 & $0.17[-0.05,0.38]$ & 0.121 & $-0.31[-0.50,-0.10]$ & $0.004^{* *}$ \\
\hline Weight & $0.07[-0.16,0.29]$ & 0.544 & $-0.05[-0.26,0.18]$ & 0.681 & $0.22[0,0.42]$ & $0.047^{*}$ & $-0.30[-0.49,0.08]$ & $0.006^{* *}$ \\
\hline BMl & $0.05[-0.17,0.27]$ & 0.628 & $-0.04[-0.26,0.18]$ & 0.695 & $0.17[-0.06,0.38]$ & 0.131 & $-0.20[-0.40,0.02]$ & 0.072 \\
\hline TV & $-0.05[-0.27,0.18]$ & 0.663 & $0.05[-0.18,0.27]$ & 0.667 & $0.13[-0.09,0.34]$ & 0.232 & $-0.25[-0.45,-0.03]$ & $0.023^{*}$ \\
\hline VC & $-0.03[-0.25,0.20]$ & 0.807 & $0.06[-0.17,0.28]$ & 0.595 & $0.21[-0.01,0.42]$ & 0.053 & $-0.23[-0.43,-0.01]$ & $0.038^{*}$ \\
\hline$\% \mathrm{VC}$ & $-0.23[-0.43,-0.01]$ & $0.038^{*}$ & $0.12[-0.10,0.34]$ & 0.261 & $0.15[-0.08,0.36]$ & 0.186 & $-0.09[-0.30,0.14]$ & 0.436 \\
\hline $\mathrm{FEV}_{1}$ & $-0.16[-0.37,0.06]$ & 0.137 & $0.07[-0.16,0.28]$ & 0.559 & $0.20[-0.20,0.41]$ & 0.067 & $-0.06[-0.28,0.17]$ & 0.613 \\
\hline $\mathrm{FEV}_{1} \%$ & $-0.21[-0.42,0.01]$ & 0.052 & $0.02[-0.20,0.24]$ & 0.858 & $0.09[-0.13,0.31]$ & 0.405 & $0.08[-0.14,0.30]$ & 0.446 \\
\hline$\% \mathrm{FEV}_{1}$ & $-0.32[-0.51,-0.10]$ & $0.003^{* *}$ & $0.11[-0.11,0.32]$ & 0.338 & $0.13[-0.10,0.34]$ & 0.245 & $0.10[-0.13,0.31]$ & 0.396 \\
\hline
\end{tabular}

Spearman's rank correlation coefficient $\left(r_{\mathrm{s}}\right)$ was calculated. ${ }^{*} p<0.05 ;{ }^{* *} p<0.01$. BMI Body mass index, $C l$ Confidence interval, $F E V$, Forced expiratory volume in

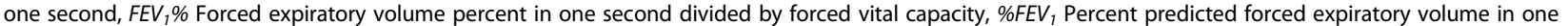
second, GOLD Global initiative for chronic obstructive lung disease, LMV Lung motion velocity, TV Tidal volume, VC Vital capacity; \%VC Percent predicted vital capacity

Table 4 Lung motion velocity in tidal and forced inspiration and expiration phases among normal, chronic obstructive pulmonary disease (COPD) mild, and COPD severe groups

\begin{tabular}{|c|c|c|c|c|c|c|c|}
\hline & \multicolumn{3}{|c|}{ Lung motion velocity, median [interquartile range] $(\mathrm{mm} / \mathrm{s})$} & \multicolumn{4}{|l|}{$p$ values } \\
\hline & (1) Normal $(n=47)$ & (2) COPD mild $(n=14)$ & (3) COPD severe $(n=22)$ & $\mathrm{All}^{\mathrm{a}}$ & (1) vs (2) ${ }^{b}$ & $(2)$ vs (3) ${ }^{c}$ & (1) vs (3) ${ }^{d}$ \\
\hline \multicolumn{8}{|l|}{ Right } \\
\hline Tidal inspiration & $16.8[14.1,19.9]$ & $28.5[21.7,33.9]$ & $25.1[17.8,31.3]$ & $<0.001^{* *}$ & $<0.001^{* *}$ & 0.432 & $0.002^{* *}$ \\
\hline Tidal expiration & $-14.5[-18.4,-11.5]$ & $-22.1[-28.6,-19.2]$ & $-15.6[-25.2,-12.9]$ & $<0.001^{* *}$ & $<0.001^{* *}$ & 0.059 & 0.206 \\
\hline Forced inspiration & $28.8[22.5,36.2]$ & $24.1[20.7,37.3]$ & $36.3[25.3,47.6]$ & 0.107 & 0.502 & 0.214 & 0.214 \\
\hline Forced expiration & $-23.6[-31.4,-18.5]$ & $-32.9[-46.6,-20.8]$ & $-27.0[-40.3,-21.9]$ & 0.093 & 0.227 & 0.810 & 0.227 \\
\hline \multicolumn{8}{|l|}{ Left } \\
\hline Tidal inspiration & $20.8[17.7,23.4]$ & $23.9[22.3,29.1]$ & $24.6[19.9,26.2]$ & $0.012^{*}$ & $0.018^{*}$ & 0.642 & 0.089 \\
\hline Tidal expiration & $-19.3[-21.5,-16.4]$ & $-25.5[-30.9,-22.0]$ & $-18.4[-23.8,-15.0]$ & $0.009^{* *}$ & $0.004^{* *}$ & $0.038^{*}$ & 0.934 \\
\hline Forced inspiration & $31.2[27.4,36.5]$ & $28.3[23.5,38.6]$ & $31.6[26.1,39.0]$ & 0.678 & 1.000 & 1.000 & 1.000 \\
\hline Forced expiration & $-27.1[-33.5,-22.0]$ & $-33.8[-43.6,-27.7]$ & $-27.8[-39.0,-21.1]$ & 0.171 & 0.166 & 0.479 & 0.650 \\
\hline
\end{tabular}

Lung motion velocity downward is defined as positive direction. ${ }^{*} p$ value $\leq 0.05$. ${ }^{*} p$ value $\leq 0.01$. ${ }^{a} p$ values are for the comparison of all groups by one-way analysis of variance on ranks. Post-hoc multiple comparison was analyzed with Holm-Bonferroni method. ${ }^{\mathrm{b}} p$ values are for the comparison between normal and COPD mild groups. ${ }^{c} p$ values are for the comparison between COPD mild and severe groups. ${ }^{d} p$ values are for the comparison between normal and COPD severe groups 
(a) tidal inspiration

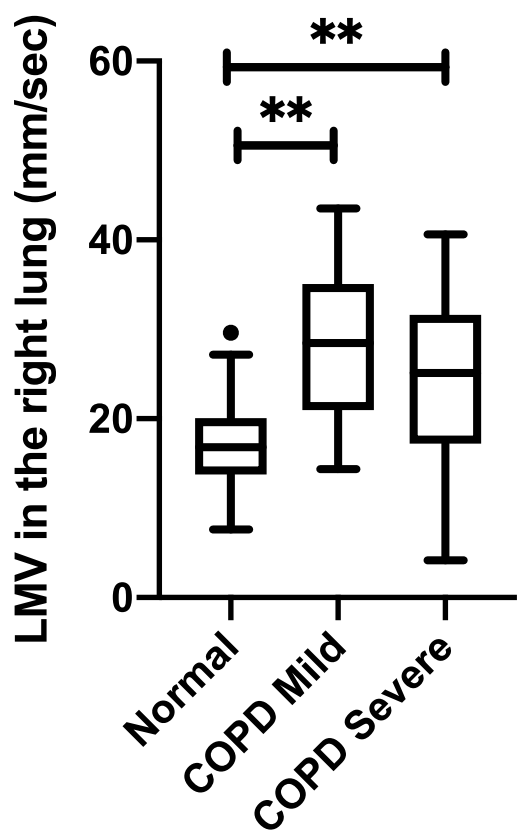

(c) tidal expiration

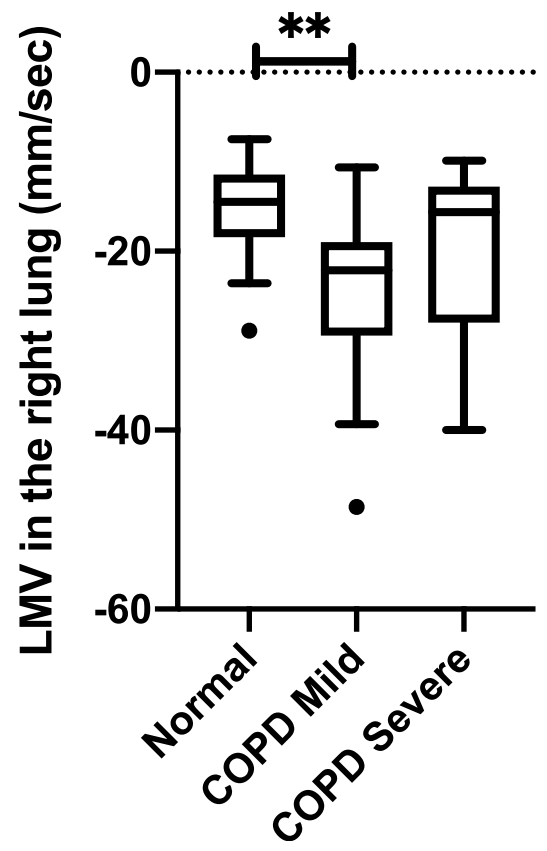

(b) tidal inspiration

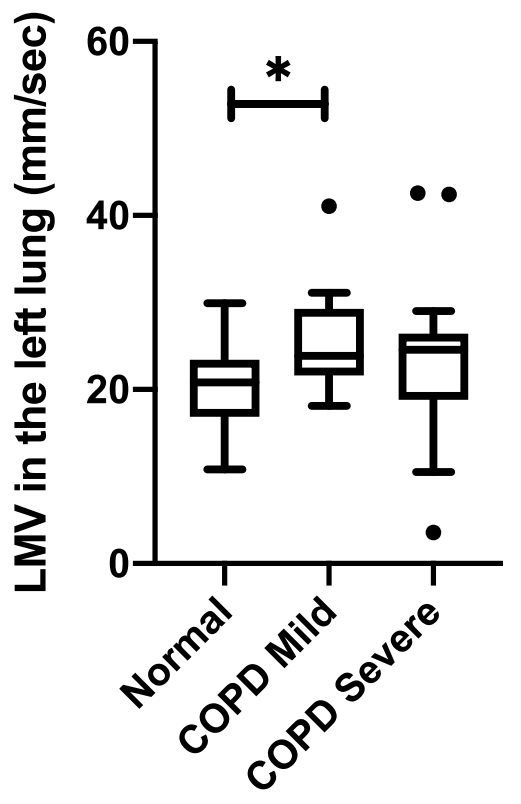

(d) tidal expiration

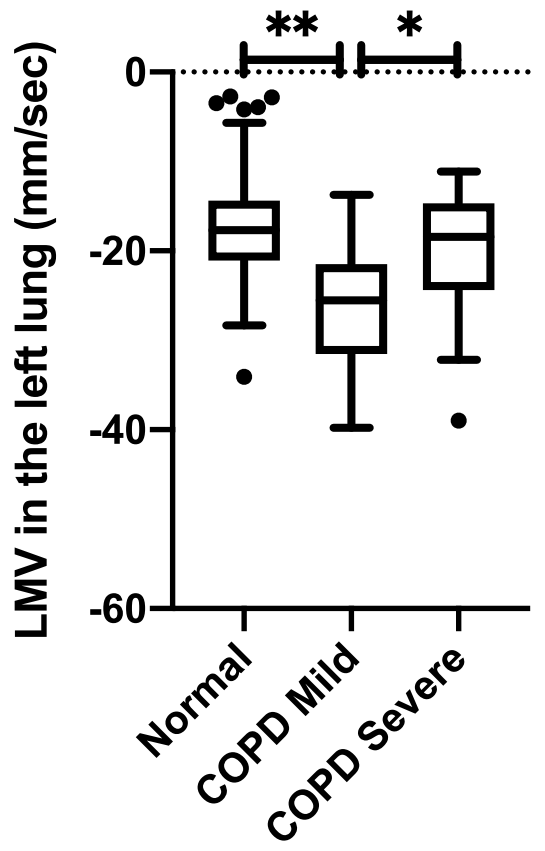

Fig. 6 Box-and-whisker plots of bilateral LMV of normal, COPD mild, and COPD severe groups in the tidal respiration. In each phase, differences between groups were investigated using one-way analysis of variance on ranks. Multiple comparisons showed that the absolute value of LMV of the COPD mild group was larger than that of the normal group with statistical significance. ${ }^{*} p<0.05 ;{ }^{* *} p<0.01$. COPD Chronic obstructive pulmonary disease, LMV Lung motion velocity 
(a) tidal inspiration

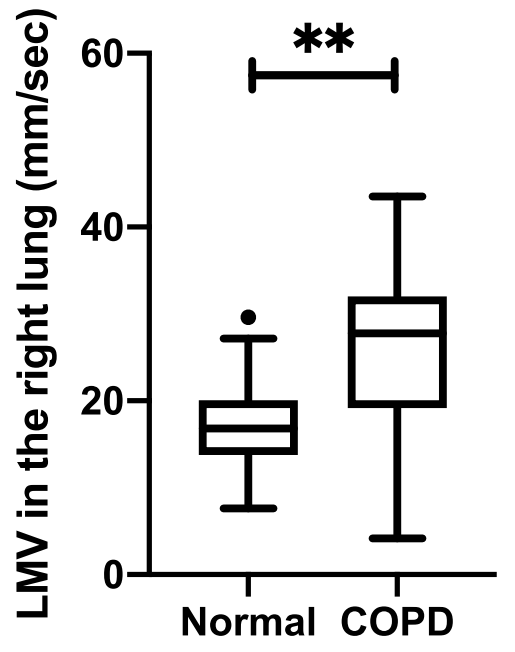

(c) tidal expiration

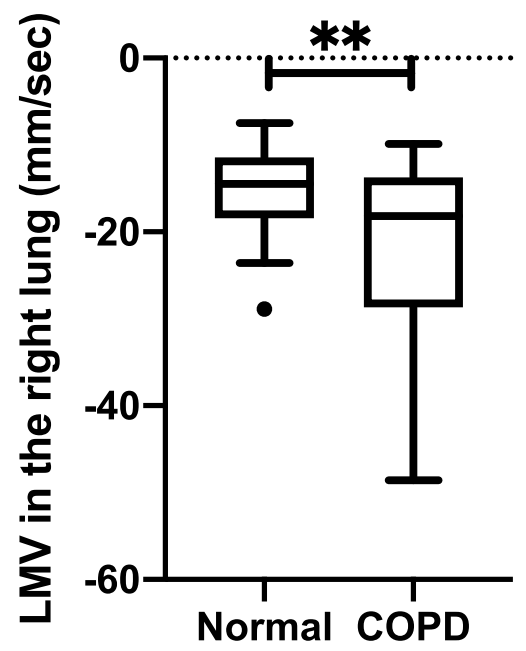

(b) tidal inspiration

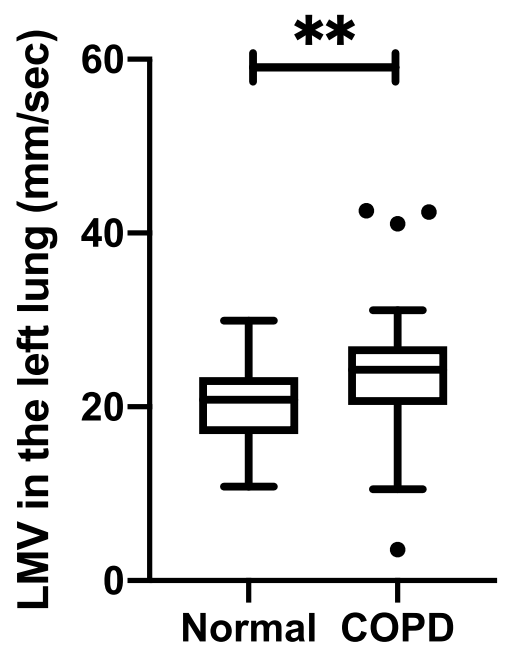

(d) tidal expiration

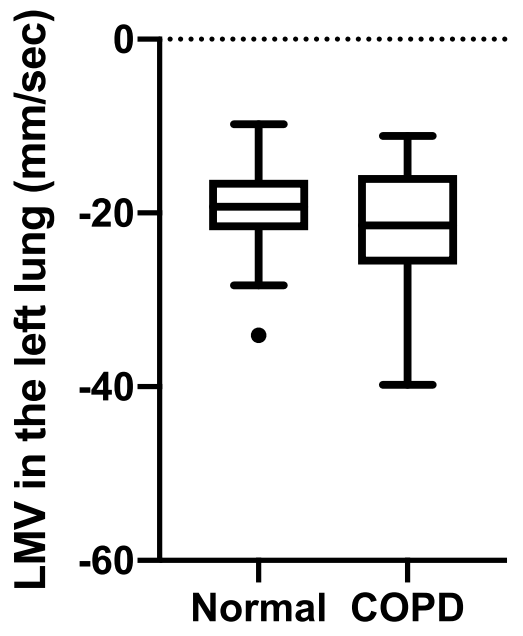

Fig. 7 Box-and-whisker plots of bilateral LMV of normal and COPD groups in tidal respiration. The lung parenchyma moved faster in COPD patients compared with normal subjects in the tidal respiration in both lungs except for the tidal expiration in the left lung. ${ }^{*} p<0.01$. COPD Chronic obstructive pulmonary disease, LMV Lung motion velocity

inspiratory phase in both lungs. VF-DXR was feasible for the assessment of lung parenchyma in patients with COPD.

\section{Abbreviations}

$\% \mathrm{FEV}_{1}$ : Percent predicted forced expiratory volume in one second; \%VC: Percent predicted vital capacity; COPD: Chronic obstructive pulmonary disease; CT: Computed tomography; DXR: Dynamic x-ray; FEV $\%$ : Forced expiratory volume percent in one second divided by forced vital capacity; $\mathrm{FEV}_{1}$ : Forced expiratory volume in one second; GOLD: Global initiative for chronic obstructive lung disease; LMV: Lung motion velocity; OFM: Optical flow method; PFT: Pulmonary function test; ROI: Region of interest; $r_{s}$ : Spearman's rank correlation coefficient; TV: Tidal volume; VC: Vital capacity; VF-DXR: Vector-field dynamic x-ray

\section{Supplementary Information}

The online version contains supplementary material available at https://doi. org/10.1186/s41747-021-00254-w.

Additional file 1. Videos of VF-DXR of Normal patient is shown in Videos 1. This case corresponds to Fig. 1.

Additional file 2. Videos of VF-DXR of COPD patient is shown in Videos 2. This case corresponds to Fig. 3. 


\section{Authors' contributions}

Takuya Hino: conceptualization, methodology, investigation, formal analysis, writing (original draft preparation), visualization. Akinori Tsunomori: methodology, software, formal analysis, writing (review and editing) visualization. Akinori Hata: writing (review and editing), methodology. Tomoyuki Hida: data curation, writing (review and editing). Yoshitake Yamada: data curation, writing (review and editing). Masako Ueyama: resources, data curation, writing (review and editing). Tsutomu Yoneyama: methodology, software, writing (review and editing). Atsuko Kurosaki: resources, data curation, writing (review and editing). Takeshi Kamitani: writing (review and editing). Kousei Ishigami: writing (review and editing). Takenori Fukumoto: methodology, software, writing (review and editing), visualization. Shoji Kudoh: resources, writing (review and editing). Hiroto Hatabu: Methodology, writing (review and editing), project administration, supervision. The authors read and approved the final manuscript.

\section{Funding}

This study was supported by grants from Konica Minolta Inc.

\section{Availability of data and materials}

The data that support the findings of this study are available from Konica Minolta Inc. but restrictions apply to the availability of these data, which were used under license for the current study, and so are not publicly available. Data are however available from the authors upon reasonable request and with permission of Konica Minolta Inc.

\section{Declarations}

\section{Ethics approval and consent to participate}

This study was approved by the Fukujuji Hospital Institutional Review Board. There is no number for IRB approval as far as we searched. Written informed consent was obtained by all the participants.

\section{Consent for publication}

The purpose of the IRB at the Japanese institute includes the consent for both presentation and publication.

\section{Competing interests}

HH was supported by NIH R01CA203636, 5U01CA209414-03, NIH/NHLBI 2R01HL111024-06, NIH R01HL135142, and NIH/NHLBI 1R01HL130974, outside the submitted work.

HH reports grants from Konica Minolta Inc. for the submitted work, grants from Canon Medical Systems Inc., other from Canon Medical Systems Inc., personal fees from Mitsubishi Chemical Inc., outside the submitted work. TA, YT, and FT are employees of the R\&D Promotion Division, Healthcare Business Headquarters, Konica Minolta, Inc.

The other authors of this manuscript declare no relationships with any companies, whose products or services may be related to the subject matter of the article.

\section{Author details}

${ }^{1}$ Center for Pulmonary Functional Imaging, Department of Radiology, Brigham and Women's Hospital and Harvard Medical School, 75 Francis Street, Boston, MA 02115, USA. ${ }^{2}$ R\&D Promotion Division, Healthcare Business Headquarters, Konica Minolta, Inc., 2970 Ishikawa-machi, Hachioji-shi, Tokyo, Japan. ${ }^{3}$ Department of Radiology, Graduate School of Medicine, Osaka University, 2-2 Yamadaoka, Suita, Osaka, Japan. ${ }^{4}$ Department of Clinical Radiology, Graduate School of Medical Sciences, Kyushu University, 3-1-1 Maidashi, Higashi-ku, Fukuoka, Fukuoka, Japan. ${ }^{5}$ Department of Diagnostic Radiology, Keio University School of Medicine, 35 Shinanomachi, Shinjuku-ku, Tokyo, Japan. ${ }^{6}$ Department of Health Care, Fukujuji Hospital, Japan Anti-Tuberculosis Association, 3-1-24 Matsuyama, Kiyose, Tokyo, Japan. ${ }^{7}$ Department of Diagnostic Radiology, Fukujuji Hospital, Japan Anti-Tuberculosis Association, 3-1-24 Matsuyama, Kiyose, Tokyo, Japan. ${ }^{8}$ Japan Anti-Tuberculosis Association, 1-3-12 Kanda-Misakicho, Chiyoda-ku, Tokyo, Japan.
Received: 15 August 2021 Accepted: 20 November 2021

Published online: 31 January 2022

\section{References}

1. Chatila WM, Thomashow BM, Minai OA, Criner GJ (2008) Comorbidities in chronic obstructive pulmonary disease. Proc Am Thorac Soc. https://doi. org/10.1513/pats.200709-148ET

2. Anthonisen NR, Connett JE, Enright PL, Manfreda J (2002) Hospitalizations and mortality in the Lung Health Study. Am J Respir Crit Care Med 166:333339. https://doi.org/10.1164/rccm.2110093

3. Jaitovich A, Barreiro E (2018) Skeletal muscle dysfunction in chronic obstructive pulmonary disease. What We Know and Can Do for Our Patients. Am J Respir Crit Care Med. https://doi.org/10.1164/rccm.20171 $0-2140 \mathrm{Cl}$

4. Wu G, Wang Q, Lian J, Shen D (2013) Estimating the 4D respiratory lung motion by spatiotemporal registration and super-resolution image reconstruction. Med Phys 40:031710. https://doi.org/10.1118/1.4790689

5. Rao F, Li WL, Yin ZP (2018) Non-rigid point cloud registration based lung motion estimation using tangent-plane distance. PLoS One 13:e0204492. https://doi.org/10.1371/journal.pone.0204492

6. Xu Y, Yamashiro T, Moriya H, et al (2018) Strain measurement on fourdimensional dynamic-ventilation $\mathrm{CT}$ : quantitative analysis of abnormal respiratory deformation of the lung in COPD. Int J Chron Obstruct Pulmon Dis 14:65-72. https://doi.org/10.2147/COPD.S183740

7. Chen D, Xie H, Zhang S, Gu L (2017) Lung respiration motion modeling: a sparse motion field presentation method using biplane $x$-ray images. Phys Med Biol. https://doi.org/10.1088/1361-6560/aa8841

8. Yamada Y, Ueyama M, Abe T, et al (2017) Time-resolved quantitative analysis of the diaphragms during tidal breathing in a standing position using dynamic chest radiography with a flat panel detector system ("Dynamic X-Ray Phrenicography"): initial experience in 172 volunteers. Acad Radiol 24:393-400. https://doi.org/10.1016/j.acra.2016.11.014

9. Yamada Y, Ueyama M, Abe T, et al (2017) Difference in diaphragmatic motion during tidal breathing in a standing position between COPD patients and normal subjects: time-resolved quantitative evaluation using dynamic chest radiography with flat panel detector system ("dynamic X-ray phrenicography"). Eur J Radiol 87:76-82. https://doi.org/10.1016/j.ejrad.201 6.12 .014

10. Hida T, Yamada Y, Ueyama M, et al (2019) Time-resolved quantitative evaluation of diaphragmatic motion during forced breathing in a health screening cohort in a standing position: dynamic chest phrenicography. Eur J Radiol 113:59-65. https://doi.org/10.1016/j.ejrad.2019.01.034

11. Hida T, Yamada $Y$, Ueyama M, et al (2019) Decreased and slower diaphragmatic motion during forced breathing in severe COPD patients: time-resolved quantitative analysis using dynamic chest radiography with a flat panel detector system. Eur J Radiol 112:28-36. https://doi.org/10.1016/j. ejrad.2018.12.023

12. Hino T, Hata A, Hida T, et al (2020) Projected lung areas using dynamic x-ray (DXR). Eur J Radiol Open 7:100263. https://doi.org/10.1016/j.ejro.2 020.100263

13. Hiasa Y, Otake Y, Tanaka R, Sanada S, Sato Y (2019) Recovery of 3D rib motion from dynamic chest radiography and $C T$ data using local contrast normalization and articular motion model. Med Image Anal 51:144-156. https://doi.org/10.1016/j.media.2018.10.002

14. Tanaka R, Sanada S, Suzuki M, et al (2004) Breathing chest radiography using a dynamic flat-panel detector combined with computer analysis. Med Phys 31:2254-2262. https://doi.org/10.1118/1.1769351

15. Hata A, Yamada Y, Tanaka R, et al (2021) Dynamic chest x-ray using a flatpanel detector system: technique and applications. Korean J Radiol. https:// doi.org/10.3348/kjr.2020.1136

16. Horn BKP, Schunck BG (1981) Determining optical flow. Artif Intell 17:185203. https://doi.org/10.1016/0004-3702(81)90024-2

17. Lin YH, Fu B, Xiao LC, Wang W, Liu PX (2013) A video smoke detection algorithm based on wavelet energy and optical flow eigen-values. J Softw 8:63-69. https://doi.org/10.4304/jsw.8.1.63-70

18. Denman S, Fookes C, Sridharan S (2009) Improved Simultaneous computation of motion detection and optical flow for object tracking. In: Proceedings of DICTA: Digital Image Computing: Techniques and Applications. Melbourne: 2009 Digital Image Computing: Techniques and Applications. https://doi.org/10.1109/DICTA.2009.35 
19. Shukla D, Patel E (2012) Speed determination of moving vehicles using Lucas-Kanade algorithm. Int J Comput Appl Technol Res 2:32-36. https://doi.org/10.7753/IJCATR0201.1007

20. Hino T, Tsunomori A, Fukumoto $T$, et al (2021) Vector-field dynamic $x$-ray (VF-DXR) using optical flow method. Br J Radiol. https://doi.org/10.1259/bjr.2 0201210

21. Vogelmeier CF, Criner GJ, Martinez FJ, et al (2017) Global Strategy for the diagnosis, management and prevention of chronic obstructive lung disease 2017 report: GOLD executive summary. Respirology 22:575-601. https://doi. org/10.1164/rccm.201701-0218PP

22. Sanchez J, Meinhardt-Llopis E, Facciolo G (2013) TV-L1 optical flow estimation. Image Processing On Line 3:137-150. https://doi.org/10.5201/ ipol.2013.26

23. OpenCV - 3.4.9. (2019) Open Source Computer Vision Library https://opencv. org/releases/page/2/ Accessed 23 Dec 2019

24. Kanda Y (2013) Investigation of the freely available easy-to-use software 'EZR' for medical statistics. Bone Marrow Transplant 48:452-458. https://doi. org/10.1038/bmt.2012.244

25. Core Team R (2020) R: a language and environment for statistical computing. R Foundation for Statistical Computing, Vienna https://www.Rproject.org/. Accessed 25 May 2020.

26. Teo PT, Crow R, Van Nest $S$ et al (2013) Tracking lung tumour motion using a dynamically weighted optical flow algorithm and electronic portal imaging device. Meas Sci Technol 24:074012. https://doi.org/10.1088/09570233/24/7/074012

27. Liu T, Merat A, Makhmalbaf MHM, Fajardo C, Merati P (2015) Comparison between optical flow and cross-correlation methods for extraction of velocity fields from particle images. Exp Fluids 56:166. https://doi.org/10.1 007/s00348-015-2036-

28. Ichiji K, Yoshida Y, Homma N, et al (2018) A key-point based real-time tracking of lung tumor in $\mathrm{x}$-ray image sequence by using difference of Gaussians filtering and optical flow. Phys Med Biol 63:185007. https://doi. org/10.1088/1361-6560/aada71

29. Aliverti A, Quaranta M, Chakrabarti B, Albuquerque AL, Calverley PM (2009) Paradoxical movement of the lower ribcage at rest and during exercise in COPD patients. Eur Respir J 33:49-60. https://doi.org/10.1183/09031936. 00141607

30. Koyama H, Ohno Y, Fujisawa $Y$ et al (2016) 3D lung motion assessments on inspiratory/expiratory thin-section CT: capability for pulmonary functional loss of smoking-related COPD in comparison with lung destruction and air trapping. Eur J Radiol 85:352-359. https://doi.org/10.1016/j.jrad.2015.11.026

\section{Publisher's Note}

Springer Nature remains neutral with regard to jurisdictional claims in published maps and institutional affiliations.

\section{Submit your manuscript to a SpringerOpen ${ }^{\circ}$ journal and benefit from:}

- Convenient online submission

- Rigorous peer review

- Open access: articles freely available online

- High visibility within the field

- Retaining the copyright to your article

Submit your next manuscript at $\boldsymbol{\nabla}$ springeropen.com 